Supplement of

\title{
Indications for a potential synchronization between the phase evolution of the Madden-Julian oscillation and the solar 27-day cycle
}

\section{Christoph G. Hoffmann and Christian von Savigny}

Correspondence to: Christoph G. Hoffmann (christoph.hoffmann@uni-greifswald.de)

The copyright of individual parts of the supplement might differ from the CC BY 4.0 License. 


\section{Analysis repeated with the epoch window cen- tered around the solar extremum}

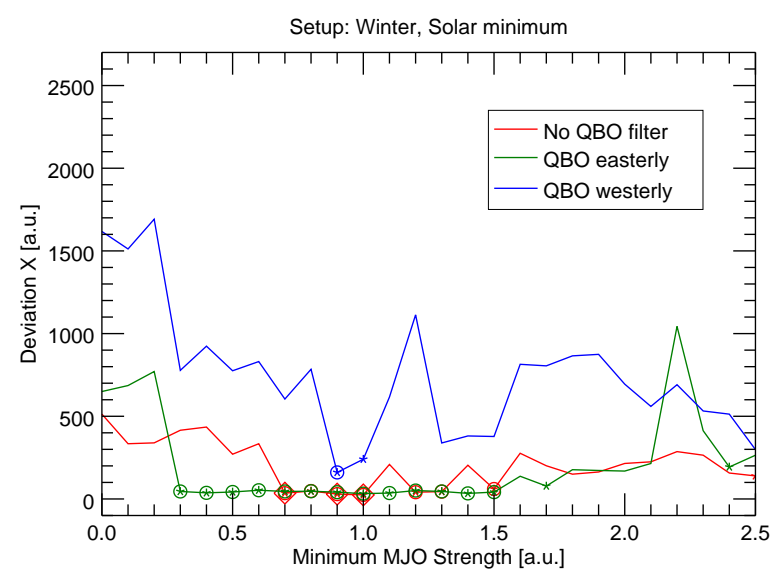

Figure S1: As Fig. 6 in the manuscript, but based on the analysis variant, in which the epochs cover \pm 14 days around solar extremum. See Sect. 4.2 in the manuscript for details.

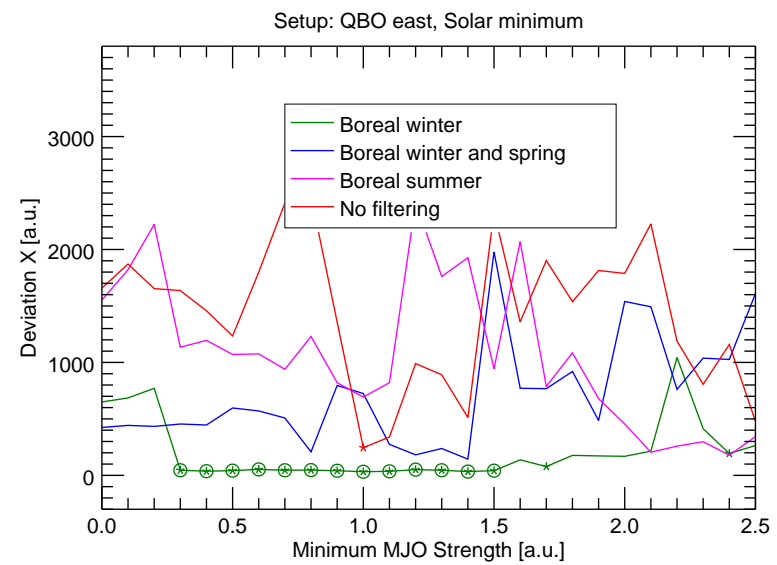

Figure S2: As Fig. 7 in the manuscript, but based on the analysis variant, in which the epochs cover \pm 14 days around solar extremum. See Sect. 4.2 in the manuscript for details. 


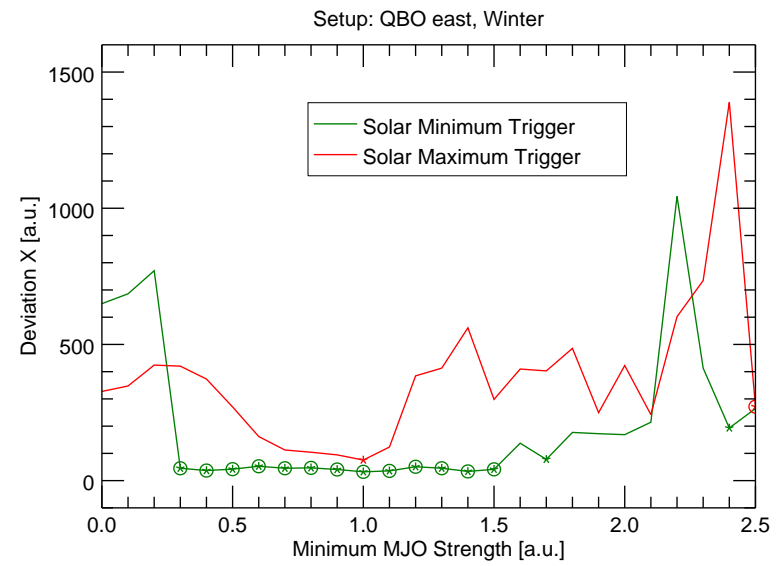

Figure S3: As Fig. 8 in the manuscript, but based on the analysis variant, in which the epochs cover \pm 14 days around solar extremum. See Sect. 4.2 in the manuscript for details.

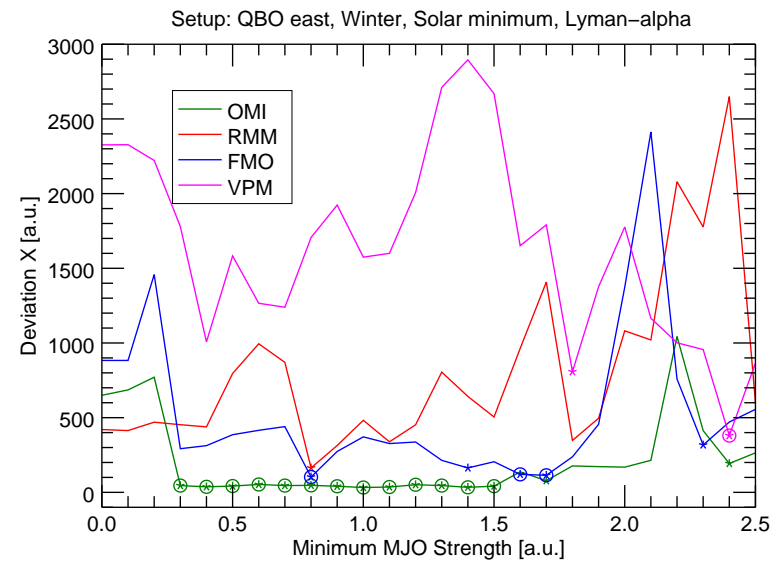

Figure S4: As Fig. 10 in the manuscript, but based on the analysis variant, in which the epochs cover \pm 14 days around solar extremum. See Sect. 4.2 in the manuscript for details. 


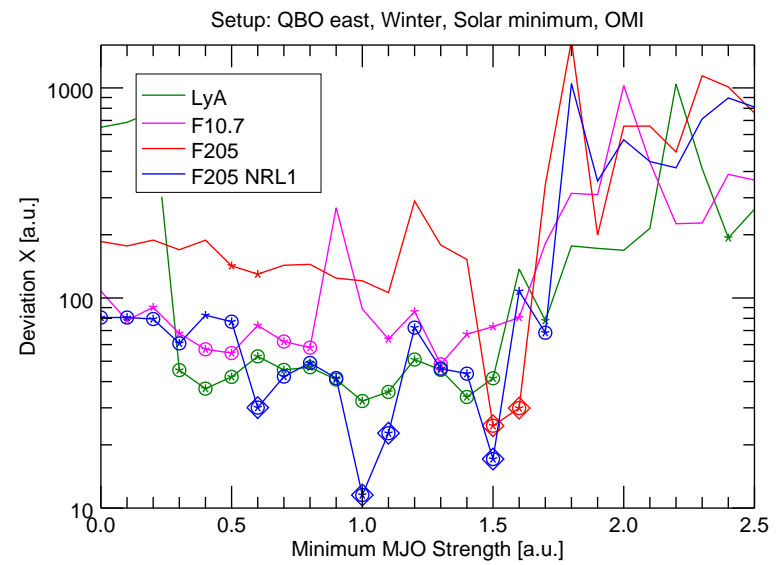

Figure S5: As Fig. 11 in the manuscript, but based on the analysis variant, in which the epochs cover \pm 14 days around solar extremum. See Sect. 4.2 in the manuscript for details. 


\section{Analysis repeated with equal weights}

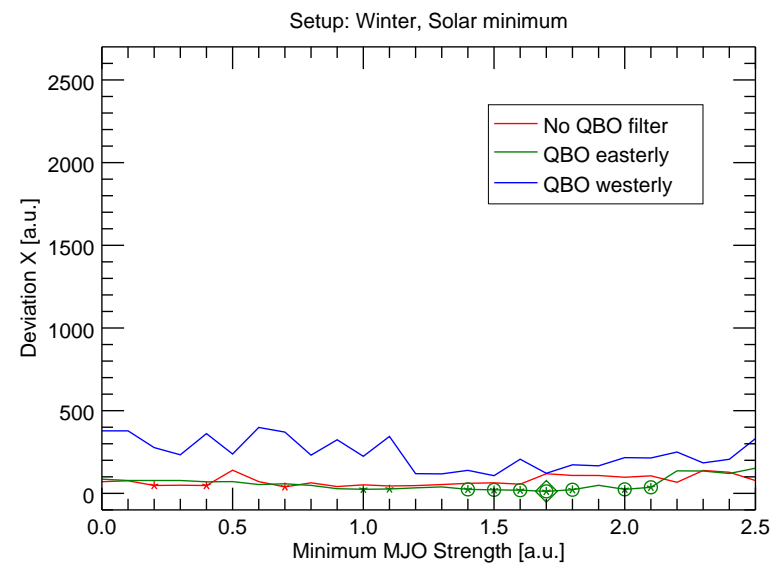

Figure S6: As Fig. 6 in the manuscript, but based on the analysis variant, in which each data point was equally weighted for the calculation of the deviation. See Sect. 4.2 in the manuscript for details.

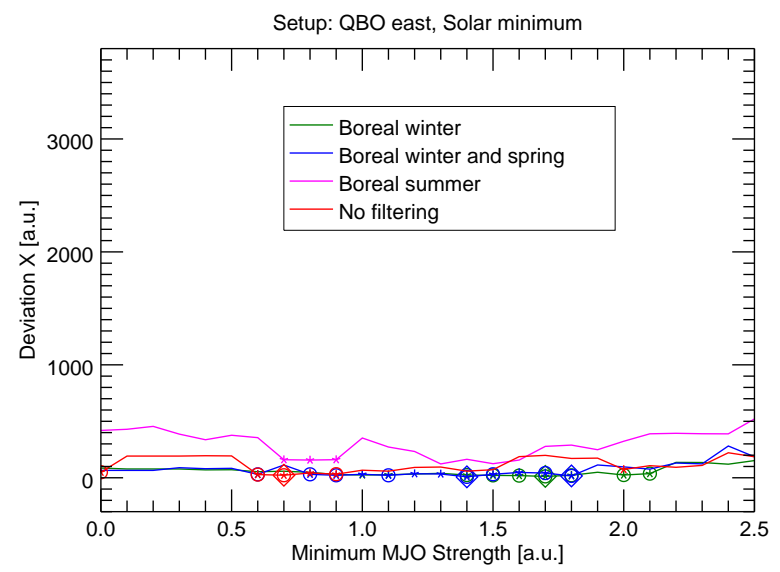

Figure S7: As Fig. 7 in the manuscript, but based on the analysis variant, in which each data point was equally weighted for the calculation of the deviation. See Sect. 4.2 in the manuscript for details. 


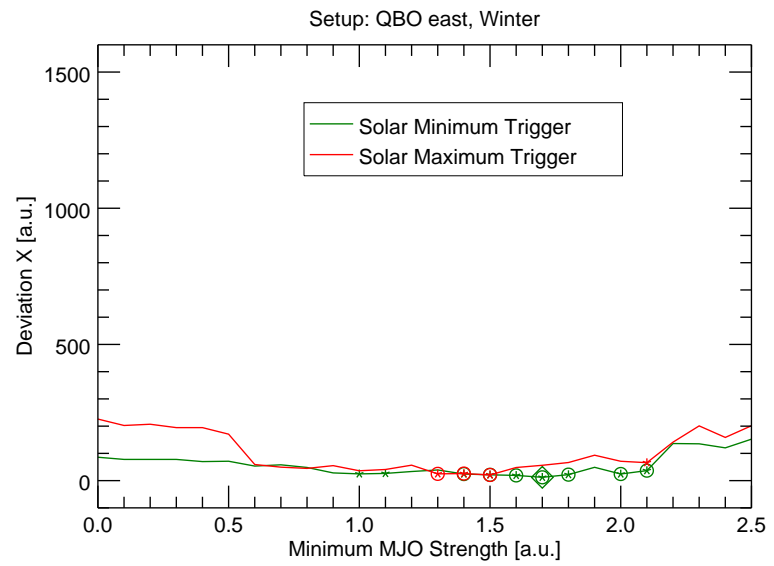

Figure S8: As Fig. 8 in the manuscript, but based on the analysis variant, in which each data point was equally weighted for the calculation of the deviation. See Sect. 4.2 in the manuscript for details.

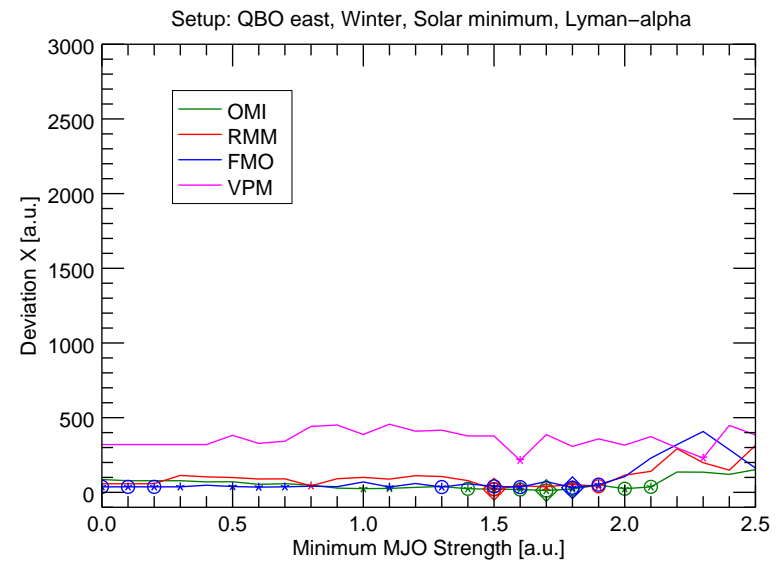

Figure S9: As Fig. 10 in the manuscript, but based on the analysis variant, in which each data point was equally weighted for the calculation of the deviation. See Sect. 4.2 in the manuscript for details. 


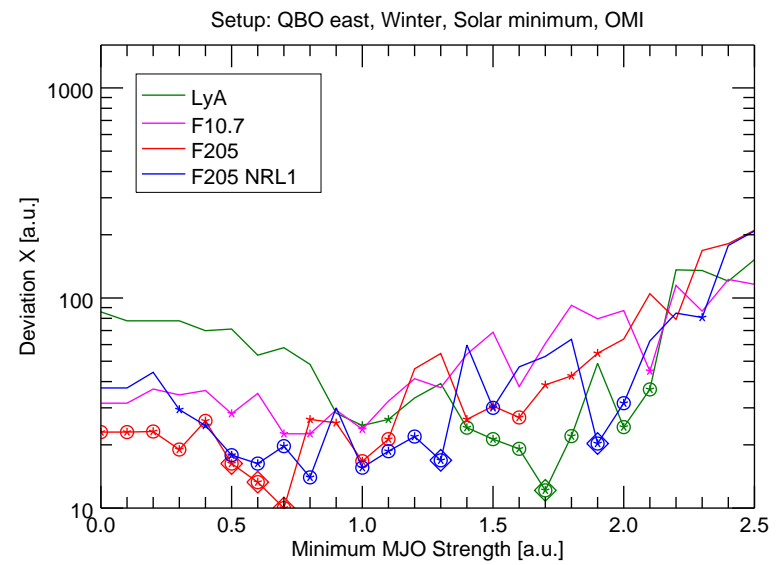

Figure S10: As Fig. 11 in the manuscript, but based on the analysis variant, in which each data point was equally weighted for the calculation of the deviation. See Sect. 4.2 in the manuscript for details. 


\section{Examples of sawtooth fits for nonoptimal fil- tering conditions}

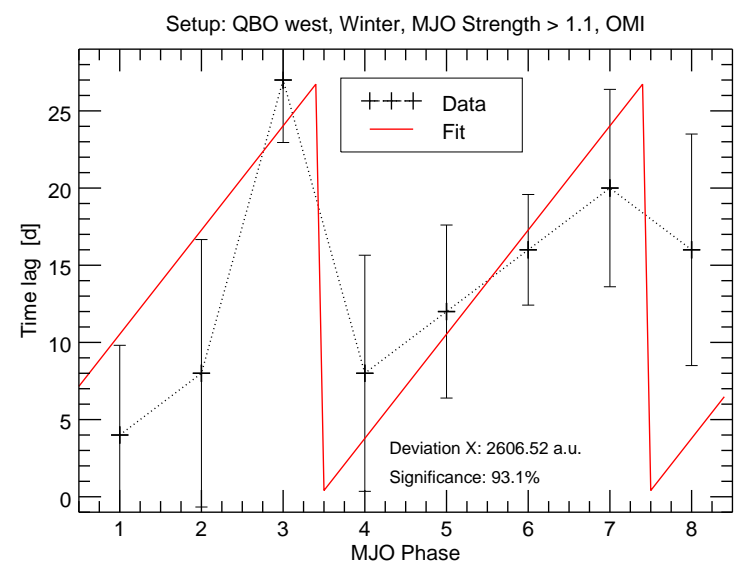

Figure S11: As Fig. 4 in the manuscript, but for QBO westerly phase conditions. The experimental setup corresponds with an MJO strength threshold of 1.1 to the weakest similarity of the QBO experiments (maximum of the blue curve in Fig. 6 of the manuscript). Nevertheless, the sawtooth shape is still rudimentarily present, albeit highly insignificant as $93 \%$ of the Monte Carlo runs resulted in lower deviations (see manuscript for details). 


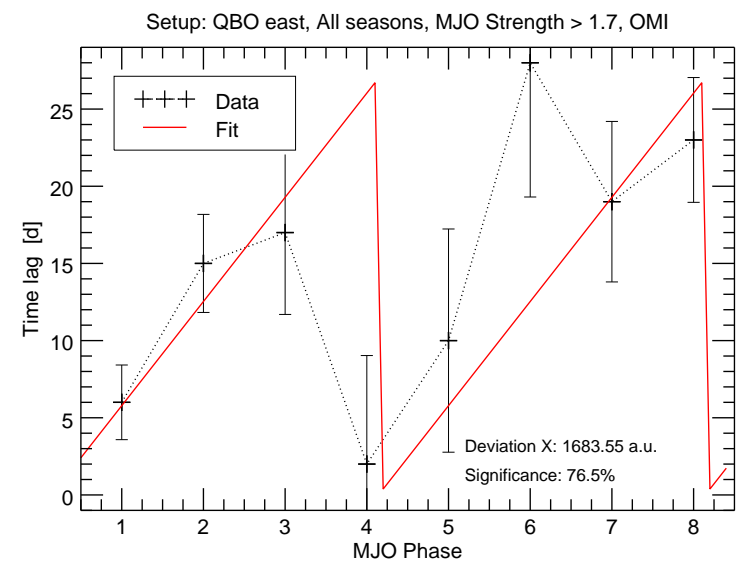

Figure S12: As Fig. 4 in the manuscript, but not filtered for seasons. The experimental setup corresponds with an MJO strength threshold of 1.7 to the weakest similarity of the all-season experiments (maximum of the red curve in Fig. 7 of the manuscript). Also here, the sawtooth shape is still rudimentarily present, albeit highly insignificant as $77 \%$ of the Monte Carlo runs resulted in lower deviations (see manuscript for details).

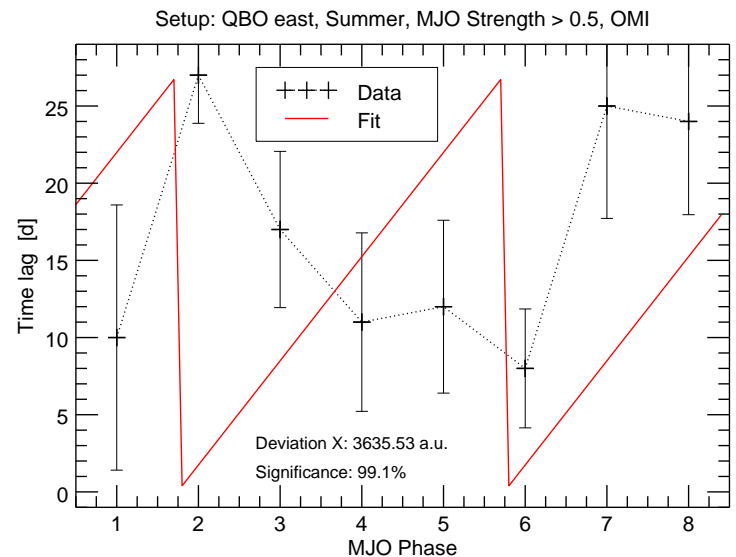

Figure S13: As Fig. 4 in the manuscript, but for summer conditions. The experimental setup corresponds with an MJO strength threshold of 0.5 to the weakest similarity of the season experiments (maximum of the magenta curve in Fig. 7 of the manuscript). 


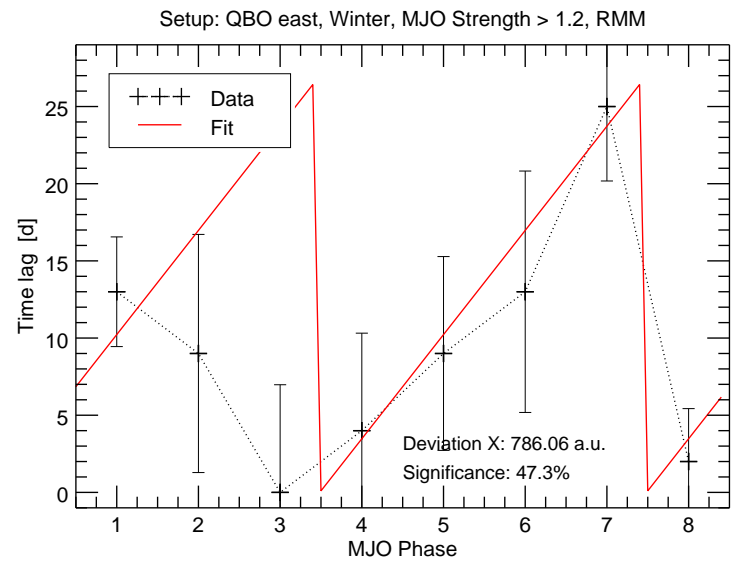

Figure S14: As Fig. 4 in the manuscript, but based on the RMM instead of the OMI index. The experimental setup corresponds with an MJO strength threshold of 1.2 to the weakest similarities of the RMM experiments (local maximum of the red curve in Fig. 10 of the manuscript). Also here, some sawtooth-like structure is still rudimentarily present, albeit highly insignificant as $47 \%$ of the Monte Carlo runs resulted in lower deviations (see manuscript for details). 


\section{Alternative definition of the QBO state by $30 \mathrm{hPa}$ winds}

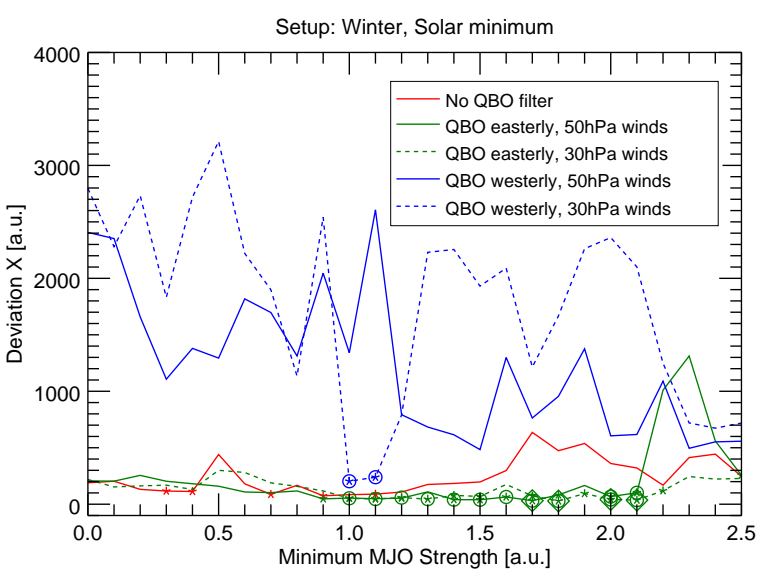

Figure S15: As Fig. 6 in the manuscript, but including results for which the QBO filtering was based on the $30 \mathrm{hPa}$ winds instead of the $50 \mathrm{hPa}$ winds. It is obvious that the choice of the pressure level, at which the wind data is evaluated to define the QBO state, does qualitatively not influence the conclusions very much, at least in the present case for boreal winter and solar minimum. Note, however, that for two cases (MJO thresholds of 1.0 and 1.1) the relation of the solar 27-day cycle and the MJO phase evolution becomes significant also for the QBO westerly phase if the QBO filtering is based on the $30 \mathrm{hPa}$ winds. This detail should be subject to future investigations. 